\title{
Regulatory Impact Analysis in Legal Research: Way Forward for Malaysian Legislation
}

\author{
Kamal Halili Hassan \\ Faculty of Law, Universiti Kebangsaan Malaysia, Malaysia \\ Email:k.halili@ukm.edu.my
}

\author{
Doi:10.5901/mjss.2015.v6n3p520
}

\begin{abstract}
This article discusses the role of a new mechanism called "regulatory impact analysis" (RIA) in enacting new or amended legislation. RIA requires an impact study of the proposed legislation on the subjects of the law (society or industry) that centers on quantitative and qualitative approaches. The quantitative approach is mainly on searching for impacts based on data and figures while the qualitative method applies a multi-criteria approach. In short, the RIA has the requirements for the making of good law. Malaysia has introduced a similar mechanism although the effort is still in its infancy. This article examines related documents on RIA in Malaysia and why it is needed.
\end{abstract}

Keywords: RIA, Malaysia, cost-benefit analysis, law, legislation

\section{Introduction}

Regulatory impact analysis (RIA) is a process of systematically identifying and assessing effects of regulatory proposals by using consistent analytical methods, such as cost-benefit analysis and multi-criteria analysis. RIA is a comparative process which is based on determining the underlying regulatory objectives sought and identifying all the policy interventions capable of achieving them. RIA has been used in virtually all OECD countries (Jacobs 1997; OECD, 2003; 2008). However, in Malaysia a systematic form of RIA has never been undertaken in the enactment of proposed legislation. As a result, some legislation has been withdrawn or not effectively enforced. The Malaysian government has suggested that the enactment of new or amended legislation be preceded by the undertaking of a RIA. The problem is that many legal researchers in Malaysia have no or little knowledge about RIA.

Regulations are an essential part of the toolkit of policy instruments that governments can use to achieve their objectives (Sunstein, 2003). Their widespread effects on different groups in society are often hidden or difficult to identify. RIA can help ensure a good understanding of how individuals and society will be affected by a regulation (Radaelli, 2004). Thus, the government needs to work systematically to ensure that the regulations they develop and implement are of high quality, since the costs of enforcing poor quality regulations are substantial (Radaelli, 2005).

The problem is that many legislations or regulations in Malaysia are enacted without undergoing RIA or only after consultation with small groups. Government Circular No 1 of 2013 titled "Policy on the development and implementation of regulations" requires all government agencies to undertake a RIA before introducing new regulations. The RIA process is under the supervision of the Malaysia Productivity Corporation.

The objective of this article is to discuss the inititive currently undertaken by the Malaysian government in using RIA as a tool for producing good and effective legislation and regulations. This article will be useful for Government agencies, local governments, statutory bodies and their officials who are involved in legal planning and enforcement.

\section{Methodology}

The research methodology is primarily qualitative. In legal research, data collection relies on primary and secondary data (Yaqin, 2007). Primary data refers to legislation, parliamentary hansards, and court cases from Malaysia and foreign countries. Secondary source are based on publications such as articles, journals, books, student theses, and official documents. The approach adopted will be a comparative analysis - adopting and modifying documents from foreign and local jurisdictions (Zahraa, 1998). For this research, primary data will be analysed based on rules of interpretation such as literal, golden, mischief, and purposive rules. Finally, all data collected will be analyed using all legal research methods, namely, historical, jurisprudential, comparative, descriptive, analytical and critical. This method is also called content analysis, although it is not based on coding as is usually done in other social science or economic research. Multi-criteria 
analysis (MCA) is also used to allow systematic and transparent decisions to be made besides enabling a quantification of major regulatory effects on cost-benefit impacts analysis. MCA basically uses the qualitative method. However, for this article, the author adopts the descritive method which is appropriate to explain this new inititive embarked by the government. This methodology is appropriate because the tool (RIA) is still new and there is currently no published example to show how RIA is used in enacting new or amended legislation/regulations.

\section{Background of RIA}

The United States developed RIA in the 1920s (Morall, 1997). It started with economists developing the methodology in counting costs and benefits in a given project. Later, other disciplines contributed to the effort by providing justifications and comments on the usefulness or otherwise of RIA in particular cost and benefit (CBA) analysis. Adler and Posner (2000) edited a book debating various issues including definitions, reform and justifications of CBA from various multi disciplinary approaches. The book shows that CBA is a rich area of interdisciplinary work although economists have defined and elaborated on the central cost-benefit methodology.

RIA's inititaive actually began from international organisations such as the OECD. Many governments of developed countries have published guidelines on how to undertake RIA on propective or new legislation. A substantial body of literature has emerged explaining the philosophy and mechanism of RIA. Its most important contribution to the quality of decisions is not the precision of the calculations used but the action of analysing, questioning, and undertaking real-world impacts and exploring assumptions (OECD, 2003). Poor quality regulations increase compliance costs for businesses and other groups, and lead to unnecessary complexity and associated uncertainty as their obligations reduce the ability of governments to achieve their objectives (OECD, 2008). The RIA framework provides a useful basis for any policy development process and not just those that may consider regulatory options or result in a cabinet paper. Hoever, the RIA requirements are formally triggered by a submission to the cabinet (NZ Treasury, 2009). A management tool is used to set the criteria of what level of risk a company is willing to accept, i.e., risk matrix. It often involves public opinion and is on a long term basis (Wilson, Mc Cuthheon, 2003).

Europe has significantly contributed to the development of the RIA with regulations there driven by competitiveness, sustainable development, and good governance. These three concepts influenced the regulatory "swing pendulum" in Europe, from the precautionary principle to regulatory impact analysis (Lofstedt, 2004). RIA has been considered a popular reform strategy in OECD countries and almost all have adopted its programmes (Jacobs, 1997). RIA is already a cornerstone for legal developments in the European Union and has been used for "better regulations" and "good regulatory governance" (Radaelli, 2004; 2005).

Industry has long been using CBA as a formal method in drafting standards for the development of safety-critical systems on an industrial scale (Bowen \& Stavridou, 1993). Any research project is always based on RIA in a comparative perspective. RIA explores all limitations and possibilities by analyzing the costs and benefits and also obtains the best practices in industry (Radaelli, 2004).

\section{RIA Initiative for Malaysian Legislation}

The Malaysian Public Service Department through its Circular No. 1 of 2013 outlines the government's policy on the development and implementation of regulations especially with regard to undertaking RIAs. The circular states that regulation-making processes must be streamlined and updated to ensure effective and fair administration besides upgrading the quality of new regulations. To that end, a RIA needs to be carried out as it has the capacity to upgrade transparency, equality, and accountability in public administration. This new government policy will create a good regulatory environment for developing sound economic conditions that will attract foreign investment and facilitate businesses. Thus, the RIA process should be based on:

(i) Sound analysis: the reasons for the introduction need to be clearly identified. The justification of the selected method is based on an analysis of the options available and after making an assessment on the impact of the alternative options;

(ii) Informed decision making: decisions makers, faced with a range of options for achieving the government's objectives, must understand the implications and be informed about the likely impact of the available options before deciding; and

(iii) Transparency: the information on which the government's regulatory decisions are based should be publicly available. (Best Practice Regulation Handbook, 2013)

The Circular further states that RIA is required to ensure that the regulations have a clear objective, taking into 
account the best alternative policy based on cost-benefit analysis, besides seeking input and views from all interested parties. In other words, a qualitative and quantitative analysis is required in ensuring the enactment of good legislation. Cost-benefit analysis is based on qualitative research and sound knowledge of micro economics is necessary for that purpose. There are instances where it may not be possible to apply qualitative research and a quantitative approach would be more appropriate. The quantitative approach here refers to an engagement of the public or industrial opinion through various mechanisms such as questionnaires, interviews, or focus group discussions.

The circular emphasizes that the requirement for RIA is only for regulations that have an impact on business, investment, and commerce. It also covers implementation aspects. Basically, a regulation coordinator must be appointed to be responsible to implement the national policy on the development and implementation of regulations. RIA must be concluded with a regulatory impact statement (RIS). The RIS process is shown in the chart below.

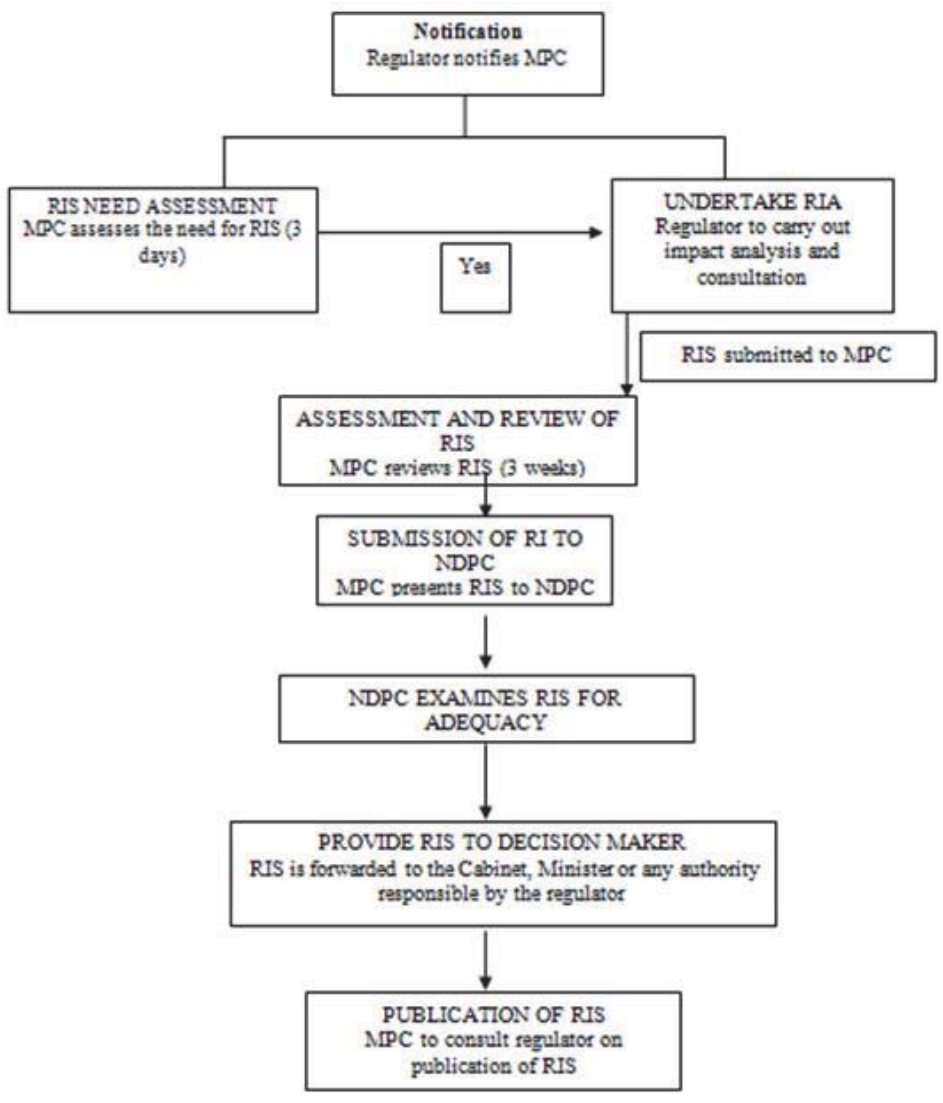

Source: Quick Reference Best Practice Regulation Handbook, July 2013, MPC.

The RIS is a document prepared by the regulator (Ministry, etc) in support of a regulatory proposal after consultation with affected parties. It records the important steps undertaken during the RIA process including assessments based on costbenefit analysis and views of other parties concerned. RIS is presented to the cabinet as the decision maker with several options (usually 3) proposed by the regulator. The three options are: (i) not doing anything, (ii) proposing a new or amended regulation; (iii) proposing a non-legal mechanism such as guidelines.

\section{Cost Benefit Analysis}

Cost benefit analysis (CBA) is the main tool in RIA; in fact some writers believe that without CBA the undertaking of RIA would be meaningless (Boardman et al, 2011). This is true to a certain extent because eventually the government would want to see the financial impact of any given project. As financial resources are scarce they have to be used for projects that yield higher results or that avoid higher risks or costs. CBA would help the government or agency to prioritize their works or plans (Layard \& Claister, 1994). Thus, CBA remains the core in RIA and without it the overall picture of a project 
or legislation would not be clearly seen. CBA was actually developed in USA in the 1920s though it was then mainly confined to economic perspectives (Teyfik, 1996). This has to be true as the economists have defined the CBA methodology especially on big government projects and plans. However, over time, experts from other disciplines have also contributed to the development of CBA especially those from philosophy, psychology, and law (Adler \& Posner, 2001).

Economists have done good technical work in elaborating on the quantitative methodology such as how to compensate variations and in discounting costs and benefits over a certain period. The purely economic CBA however has been challenged where there are scenarios or situations which cannot be surveyed quantitatively (Wilson \& McCuthheon, 2003). In certain scenarios, employing some other methodology would be better such as quality-based assessment or (non-monetized) multi dimensional assessment. Thus, the normative justifications for CBA have emerged explaining how a given project can be assessed without necessarily using the economic CBA methodology. Debates on the usefulness or otherwise of the CBA have arisen from time to time but it is not the purpose of this article to elaborate on it. Suffice to say that it has its own supporters and detractors, and is now viewed from many perspectives although the economic factor remains the primary consideration underlying it.

\subsection{Local Experience}

The Department of Occupational Safety and Health, Malaysia (DOSH) has assigned the author and his group to undertake an RIA relating to the amendment of the Occupational Safety and Health Legislation. Legislations pertaining to industrial safety in Malaysia are the Occupational Safety and Health Act 1994 (OSHA) and the Factories and Machinery Act 1967 (FMA). These two Acts which are enforced simultaneously have caused some problems to the DOSH and the industry. There are provisions of the Acts which address the same subject-matter but are inconsistent against each other, and there are also matters which are unclear as to whether DOSH has the power to act or not. Provisions which are too cumbersome and costly for DOSH to act upon require review; for example, whether there is the need to inspect all machines regardless of their potential to danger at work places. Currently, significant resources are spent by DOSH to inspect low risk machineries which in fact contribute to a very small number of injuries or fatalities in the workplace. The legal requirement to inspect machines every 15 months needs to be reexamined together with the suggestion that highrisk machinery inspections be extended to once every 5 years. The intervals between inspections can be extended under the proposed amendment provided an employer manages to show capability in managing the risk properly. Against these issues, DOSH has proposed to re-examine the legislation with the possibility of merging the two Acts. Malaysia should undertake RIA for this purpose, and the most important activity in this assessment is to measure the financial implications of the proposed merger of the Acts including the introduction of new provisions.

For evaluating the financial implications using CBA a questionnaire was distributed to employers in various economic sectors to collect relevant data on number of machines, time taken, and cost involved in implementing the new provisions. Data was also directly collected from DOSH. The data was collated and projections made for a specific duration (10 years) to measure the costs and benefits. Beside the CBA, a qualitative evaluation was also conducted for analyzing the implications of the proposed merger of the legislations. This new experience of undertaking RIA in proposing a new or amended Act (OSHA) arguably is the beginning of a new era in law-making in Malaysia. It is already proven elsewhere that safety regulation would be effective if RIA (CBA) is undertaken before its enactment (Wilson \& McCuthheon, 2003; Bowen \& Stavridou, 1993).

\section{Conclusion}

The RIA manual can be used by the government and researchers in analysing the impact of proposed legislation or regulations on society. It will be good for the economy of the country as it will increase the efficiency and effectiveness of law making. This is a new endeavour in Malaysia as previously no proper RIA was carried out prior to enacting legislation. The effect of making laws without the benefit of RIA is that some legislation has been withdrawn or not effectively enforced. With this new requirement put in place before an Act or regulation is legislated, it is hoped that Malaysia will produce good law for the country and its people.

\section{Acknowledgment}

The author would like to record his appreciation to the Ministry of Education, Malaysia for providing a research grant No: FRGS/2/2013/SS110/UKM/01/1 to enable this research and article to be produced. 


\section{References}

Adler MD, Posner EA., 2001. Cost-benefit Analysis Legal, Economic and Philosophical Perspectives Chicago \& London: The University of Chicago Press.

Boardman EB, Greenberg DH, Vining AR, Weimer DL. 2011. Cost-Benefit Analysis: Concepts and Practice, 4th Ed. New Jersey: Prentice Hall.

Bowen, J \& Stavridou, V. 1993. Safety-critical systems, formal methods and standards, Software Engineering Journal, pp 189-210.ieeexplore.ieee.org.

Jacobs, SH. 1997. An overview of regulatory impact analysis in OECD countries, in Regulatory Impact Analysis - Best Practices in OECD Countries. USA: OECD: 13-30.

Hahn R, J Burnett, Chan YH, Mader E, Moyle P., 2000. Assessing the quality of regulatory impact analyses, www.papers.ssrn.com.

Layard R, Claister S. 1994. Cost-Benefit Analysis, Cambridge University Press.

Löfstedt, RE. 2004. The swing of the regulatory pendulum in Europe: from precautionary principle to (regulatory) impact analysis. Journal of Risk and Uncertainty, 1-39.

Malaysia Productivity Corporation, 2013. Quick Reference Best Practice Regulation Handbook, Kuala Lumpur: MPC.

Morall , JF, 1997. An assessment of the US regulatory impact analysis program in Jacobs, SH, Regulatory Impact Analysis - Best Practices in OECD Countries. USA: OECD: 71-88.

NZ Treasury. 2009. Regulatory Impact Analysis.(www.treasury.govt.nz/publications/guidance/regulatory/impactanalysis

OECD. 2003. Regulatory policies on OECD countries: From interventions to regulatory governance.

OECD. 2008. Introductory Handbook for Undertaking Regolatory Impact Analysis (RIA). www.oecd.org/gov/regulatory-policy.

Teyfik F Nas. 1996. Cost-Benefit Analysis: Theory and Application, Sage Publication.

Radaelli, CM. 2004. The diffusion of regulatory impact analysis - Best practice or lesson-drawing? European Journal of Political Research, 43(5): 723-747.

Radaelli, CM. 2005. Diffusion without convergence: how political context shapes the adoption of regulatory impact assessment. Journal of European Public Policy, 924-943. Taylor \& Francis.

Sunstein CR. 2003. The Cost-Benefit State: The Future of Regulatory Protection. American Bar Association.

Wilson, L \& McCuthheon, D. 2003. Industrial safety and risk management. Canada: The University of Alberta Press.

Yaqin, A. 2007. Legal research and writing, LexisNexis, Malaysia: Petaling Jaya.

Zahraa, M.1998. Research method for law postgraduate overseas students, Kuala Lumpur: Univision Press. 